\title{
Atividades com Comunicação \& Educação Ano XI - N. 2
}

Ruth Ribas Itacarambi Doutora pela Faculdade de Educação da USP.

Educadora e pesquisadora do CAEM-Centro de Aperfeiçoamento do Ensino da Matemática do IME-USP. Professora da FOC - Faculdade Osvaldo Cruz. Membro da Equipe SiteEducacional.

E-mail: ruthri@uol.com.br

Apesar de todos os estudos sobre teorias de ensino e aprendizagem e suas metodologias, a escola está centrada em propostas de instrução nas quais o professor ensina, dá aula, e o aluno escuta, toma nota para reproduzir as informações na prova. A recente discussão sobre alfabetização veiculada nas mídias é um exemplo do que acontece com a maioria das escolas em nosso país. Este artigo pretende discutir esta questão na perspectiva do jovem e cabe perguntar: que novas formas de ensinar são necessárias para os jovens na sociedade do conhecimento (século XXI)?

A reflexão sobre tal pergunta tem como ponto de partida os artigos de Maria Cristina C. Costa, O que aprendi com educação a distância, de Fabiano A. Curi, Uma proposta para a leitura crítica dos videogames, e de Dirce M. Pranzetti, Maria Cecília Toloza e Maria Izabel de A. Leão, Projeto Clicar: entre o lúdico e a compreensão.

O outro ponto para reflexão é: a melhor maneira de aprender não é escutar aula, mas pesquisar e elaborar novas idéias, por meio de atividades de reconstrução do conhecimento. O jovem, no desenvolvimento dessas atividades e sob a orientação do professor, constrói sua autonomia, tem contato com os métodos científicos e passa a lidar com os conteúdos de forma criativa.

Como apoio a essa forma de entender a aprendizagem, em que o jovem está em constante produção do conhecimento e sempre tem o direito de refazer sua atividade, dentro do tempo previsto, foram escolhidos os artigos de Mayra R. Gomes, Perfis: modos de inserção de jornais televisivos, e de Walter de Sousa Junior, Apropriações melodramáticas: o caso Pedrinho no Jornal Nacional $e$ em Senhora do Destino.

Na sociedade do conhecimento, aprender deixa de ser função apenas da escola e, a partir de determinada idade, passa a ser um direito permanente tanto para a inserção mais favorável no mercado de trabalho como para o exercício pleno da cidadania. Essas idéias são abordadas com base nos artigos de João 
A. Carrascoza, Uma propaganda exemplar do governo Lula, de Luciano Somenzari, A luta contra o desemprego: os portões de fogo da atualidade, e de Roseli Fígaro, A arte de Elifas Andreato.

As três atividades com os artigos desta edição da revista têm como propósito apresentar sugestões para serem desenvolvidas em sala de aula, discutindo as novas formas de ensino e aprendizagem, promovendo a interação entre as diferentes áreas do conhecimento na perspectiva da sociedade atual.

\section{PRIMEIRA ATIVIDADE}

\section{Mexendo no formato instrucional:}

\section{novas formas de ensinar e de aprender}

A atividade objetiva discutir as novas formas de ensino e aprendizagem na sociedade do conhecimento, sua organização e o uso dos meios de comunicação como a EAD - Educação a Distância, que, tal como as atividades em mídias impressas, precisam ser planejadas e estruturadas. $\mathrm{O}$ artigo, $O$ que aprendi com educação a distância, é o apoio para esta atividade, pois, segundo sua autora, a primeira preocupação é estruturar as atividades a distância e dosá-las, criando certo ritmo de trabalho; esta forma de trabalhar modifica a dinâmica da sala de aula.

A atividade que propomos é para grupos de formação e profissionais da educação e comunicação; pode ser um trabalho coletivo que começa nas reuniões de planejamento e organiza-se na seguinte seqüência pedagógica:

1) Fazer a leitura individual do artigo citado, registrando as principais dificuldades para desenvolver o trabalho com novas mídias, tendo como referência os itens: A experiência com novas mídias e Metodologia de trabalho do artigo.

2) Por ser um trabalho coletivo, discutir o texto com os demais participantes, fazer um rol das dificuldades levantadas na leitura e procurar alternativas para superá-las.

3) Ler os itens vantagens, desvantagens e nem vantagens, nem desvantagens do artigo e comparar com as dificuldades registradas pelo grupo.

4) Sintetizar, analisando as desvantagens relatadas pela autora e as outras dificuldades que forem apontadas pelo grupo.

É importante lembrar que as desvantagens têm sido apresentadas pelos profissionais para justificar o não-envolvimento em trabalhos on-line. Citamos algumas: os professores e/ou alunos não são usuários assíduos da internet; a escola não tem acesso à internet; os professores não têm tempo para organizar as atividades utilizando a rede; a escola não tem acesso a um ambiente de aprendizagem (e-learning); entre outras. Essas dificuldades, na sua maioria, não são exclusivas dos trabalhos on-line. Já as questões técnicas, como a do ambiente de aprendizagem, o são, e podem ser contornadas com os espaços frees existentes na rede, como: blogs, listas de e-mails, grupos de discussão etc. Nesse sentido, sugerimos a leitura do artigo Projeto Clicar: entre o lúdico e a compreensão, que trata de um projeto desenvolvido pela Estação Ciência, o qual utiliza alguns dos recursos citados. 
O artigo Uma proposta para a leitura crítica dos videogames dá continuidade à discussão sobre novas formas de ensinar e de aprender. Seu autor tem como objetivo chamar a atenção dos professores para o fato de que os jogos são parte da vida dos jovens e elementos na construção de sua visão de mundo. A ação educativa sugerida é proporcionar aos alunos que jogam videogames uma leitura crítica de seu entretenimento, empregando conhecimentos adquiridos no processo dialógico em sala de aula.

O artigo é um meio para a reflexão sobre os videogames na sala de aula.

1) Solicitar que os alunos façam uma relação dos jogos que usam como entretenimento no seu cotidiano. Os jogos podem ser individuais ou coletivos, eletrônicos ou não.

2) Sugerir que os alunos, em grupo, discutam os enredos dos jogos relacionados e verifiquem se existem laços com outros meios de comunicação, como o cinema ou revista em quadrinhos.

3) Fazer um quadro com as opiniões dos alunos e analisá-las; como subsídio para essa tarefa, os alunos podem ler o artigo proposto e verificar como o autor tratou os enredos e as relações dos videogames com as demais mídias.

4) Trazer para a sala de aula alguns videogames escolhidos e discutir com os alunos os assuntos, valores, estereótipos e preconceitos presentes em seus enredos. Para subsidiar o professor, nesta análise, sugerimos a leitura da proposta do autor e o texto de Paulo Freire de sua referência bibliográfica ${ }^{1}$.

5) Solicitar que os alunos, em grupo, escolham um enredo e criem um jogo que pode ou não envolver as mídias digitais.

6) Sintetizar as criações na sala de aula, destacando a importância da construção do conhecimento e que "aprendizagem não se define no professor, e sim no aluno"2.

\section{SEGUNDA ATIVIDADE Pesquisar para reconstruir o conhecimento}

O objetivo da atividade é chamar a atenção dos profissionais da educação para a seguinte realidade "descobrir novas formas de participação e comunicação que falem o idioma dos alunos" . Com isso queremos dar continuidade à discussão sobre o jovem, suas possibilidades e a liberdade de expressar o mundo e o seu mundo; o jovem que está em constante produção de conhecimento. Nessa perspectiva consideramos fundamental habituar o jovem a ler, a passar por dentro do texto, desconstruindo sua argumentação e logo reconstruindo com suas palavras. Para esta proposta escolhemos os artigos Perfis: modos de inserção de jornais televisivos e Apropriações melodramáticas: o caso Pedrinho no Jornal Nacional $e$ em Senhora do Destino.

A atividade que propomos aos professores tem a seguinte seqüência didática:

1) Solicitar aos alunos a leitura crítica do artigo Apropriações melodramáticas, e que grifem as idéias do texto mais significativas para eles e aquelas com as quais não concordarem.
1. FREIRE, Paulo. A importância do ato de ler. São Paulo: Cortez, 1992.

2. OROZCO GÓMEZ, Guilhermo. Professores e meios de comunicação: desafios e estereótipos. Revista Comunicação \& Educação, São Paulo: CCA/ECA-USP/Moderna, n. 10, p. 65, set./dez. 1997.

3. MARTÍN-BARBERO, Jesús. Dos meios às mediações: comunicação, cultura e hegemonia. Rio de Janeiro: UFRJ, 2001. 
2) Pedir que os alunos identifiquem o gênero narrativo e o tipo de linguagem utilizados nas reportagens, e como são definidos no artigo.

3) Diante da posição do autor de mostrar semelhanças entre a narrativa de teleficção e as reportagens sobre o caso Pedrinho, fazer algumas perguntas provocadoras: Quais são os argumentos que o autor utiliza para apoiar seu ponto de vista? Como as imagens são apresentadas pelo autor? Quais são os elementos melodramáticos que o autor aponta para justificar que a cobertura do JN é um gênero narrativo e estético de melodrama?

4) Propor a elaboração de um roteiro para entrevistar pais ou membros da comunidade que costumam assistir ao telejornal e à novela, e que, em particular, tenham assistido à novela Senhora do Destino.

5) Discutir com os alunos o objetivo da entrevista: verificar se usuários da mídia TV identificam as reportagens do JN sobre o caso Pedrinho com o drama da novela Senhora do Destino.

6) Organizar e interpretar os dados da entrevista tendo presentes os pressupostos do artigo.

7) Concluir pedindo para os alunos assistirem aos telejornais citados no artigo Perfis - Jornal Nacional, Jornal da Record e Jornal da Cultura. Registrar os temas tratados nos três telejornais em um dia escolhido pelos alunos ou em uma semana. Selecionar uma matéria comum aos três telejornais e pedir que elaborem um texto narrativo no qual apresentem a opinião deles de como o tema foi tratado em cada emissora.

8) Fazer uma síntese das redações discutindo os diferentes pontos de vista dos jornais e dos alunos. Para subsidiar o professor no encaminhamento deste trabalho, sugerimos a leitura do artigo Perfis, citado.

\section{TERCEIRA ATIVIDADE}

\section{Mercado de trabalho e exercício da cidadania}

$\mathrm{O}$ artigo A luta contra o desemprego: os portões de fogo da atualidade aborda a questão do desemprego, que é uma das principais preocupações dos jovens que estão saindo da escola para o mercado de trabalho. Algumas medidas institucionais vêm sendo propostas, como o Programa Nacional de Estímulo ao Primeiro Emprego (PNPE) e, segundo o artigo, a Central de Trabalho e Renda (CTR); entretanto, em todas elas se faz necessário aprimorar os processos de comunicação de modo que o jovem possa ter acesso às informações e mesmo à qualificação profissional.

Esta atividade é dirigida a dois públicos complementares: alunos do Ensino Médio ou de escolas técnicas que estão saindo para o mercado de trabalho e alunos de graduação de diferentes áreas do conhecimento.

1) Solicitar a leitura e a síntese das principais idéias do artigo.

2) Registrar as principais ações que o CTR desenvolve no sentido de ajudar o trabalhador a buscar uma vaga no mercado, assim como promover sua qualificação. 
3) Solicitar que os alunos consultem sites da internet que tratam da questão da busca de qualificação profissional e de emprego. Sugerimos o site do PNPE: <http:/ /www.mte.gov.br/FuturoTrabalhador/primeiroemprego >.

4) Registrar as informações sobre vagas disponíveis perto de suas residências e programas de qualificação.

5) Retomar os registros em sala de aula, analisando as intenções de cada site, sua veiculação política e a pertinência dos dados para o grupo de alunos. Criar um banco de dados com as informações que o grupo considerar importantes e divulgar em um mural de fácil acesso à comunidade.

6) Resumir o trabalho levando em conta que muitos dos programas apresentados pelas instituições são campanhas publicitárias, em especial as propagandas do governo, qualquer que seja o partido no poder. Para subsidiar a discussão, sugerimos a leitura do artigo Uma propaganda exemplar do governo Lula.

A leitura da entrevista no artigo A arte de Elifas Andreato, no encerramento da atividade, objetiva colocar o jovem em contato com uma experiência de vida e trabalho. Experiência esta que valoriza a dimensão humana e conscientiza o jovem sobre a importância de estudar e de ter uma formação cultural ampla.

Resumo: As três atividades com os artigos desta edição da revista têm como propósito apresentar sugestões para serem desenvolvidas em sala de aula, discutindo as novas formas de ensino e aprendizagem, promovendo a interação entre as diferentes áreas do conhecimento na perspectiva da sociedade atual. Para a primeira atividade foram eleitos os artigos $O$ que aprendi com educação a distância, Uma proposta para a leitura crítica dos videogames e Projeto Clicar. Para a segunda atividade, os artigos Modos de inserção de jornais televisivos e Apropriações melodramáticas: o caso Pedrinho no Jornal Nacional e em Senhora do Destino. Na terceira atividade as idéias são abordadas a partir dos artigos Uma propaganda exemplar do governo Lula, A luta contra o desemprego: os portões de fogo da atualidade e $A$ arte de Elifas Andreato.

Palavras-chave: comunicação e educação, ensino e aprendizagem, educação a distancia, sociedade do conhecimento.
Abstract: The three activities with this issue articles have as objective introducing suggestions of work in classroom, discussing the new ways of teaching and learning, promoting the interaction among different knowledge areas in the perspective of present society. For the first activity were elected the articles What I have learnt with long distance education (O que aprendi com educação a distância), A proposal for the critical reading of videogames (Uma proposta para a leitura crítica dos videogames), and Clicar Project (Projeto Clicar). For the second activity, the articles Profiles: insertion modes of television news (Perfis: modos de inserção de jornais televisivos), Melodramatic appropriations: the case of Pedrinho in Jornal Nacional and in the Lady of Destiny (Apropriações melodramáticas: o caso Pedrinho no Jornal Nacional e em Senhora do Destino). In the third activity, ideas are approached from the articles An exemplar propaganda of Lula's government (Uma propaganda exemplar do governo Lula), The fight against unemployment: the gates of fire in present days (A luta contra o desemprego: os portões de fogo da atualidade), and The art of Elifas Andreato ( $A$ arte de Elifas Andreato).

Keywords: communication and education, teaching and learning, distance education, knowledge society. 